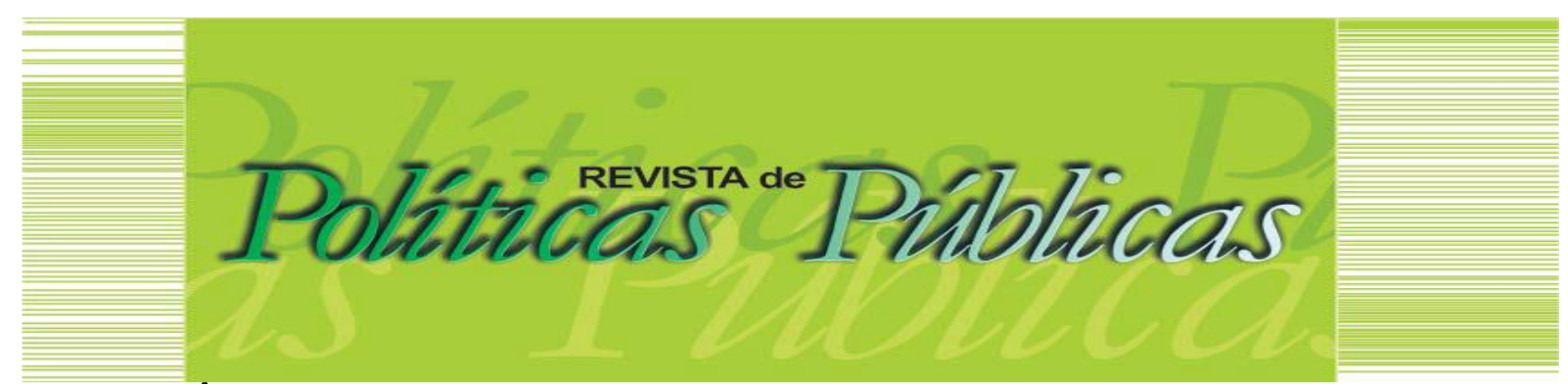

\title{
ASSISTÊNCIA SOCIAL NO NEOLIBERALISMO: uma análise no contexto da pandemia da COVID-19
}

Robson Roberto Silva 1

\begin{abstract}
Resumo
Apesar de a assistência social ter sido incluída na Constituição Federal de 1988 como uma das políticas de seguridade social, ela tem sido desde então marcada por tensões e resistências entre sujeitos que pertencema classes e a grupos sociais antagônicas. 0 presente artigo procura, assim, demonstrar, por meio de uma pesquisa bibliográfica e documental, as principais contradições na área da assistência social determinadas pela dinâmica da neoliberalização no Brasil. Particularmente, busca examinar,no contexto da pandemia da COVID-19, as medidas adotadas pelo governo ultraneoliberalde Bolsonaro, que vem reforçando a manutenção de uma estrutura de ações paralelas, focalizadas e seletivas nessa área social, que não se configuram como direitos assistenciais.
\end{abstract}

Palavras-chave: Assistência social. Neoliberalismo. Pandemia da COVID-19. Brasil.

SOCIAL ASSISTANCE IN NEOLIBERALISM: an analysis in the context of the COVID-19 pandemic

\section{Abstract}

Although social assistance was included in the Federal Constitution of 1988 as one of the social security policies, it has since been marked by tensions and resistance between subjects belonging to antagonistic classes and social groups. This article thus seeks to demonstrate, through bibliographical and documentary research, the main contradictions in the area of social assistance determined by the dynamics of neoliberalization in Brazil. In particular, it seeks to examine, in the context of the COVID-19 pandemic, the measures adopted by the ultra-neoliberal government of Bolsonaro, which has been reinforcing the maintenance of a structure of parallel, focused and selective actions in this social area, which do not constitute assistance rights.

Keywords: Social assistance. Neoliberalism. COVID-19 pandemic.Brazil.

Artigo recebido em: 30/11/2020 Aprovado em: 20/05/2021

DOI: http://dx.doi.org/10.18764/2178-2865.v25n1p26-45

${ }^{1}$ Assistente Social. Doutor em Serviço Social pela Universidade Federal do Rio de Janeiro (UFRJ). Professor Adjunto da Escola de Serviço Social (ESS) da Universidade Federal Fluminense (UFF).

E-mail: robson.essuff@gmail.com 


\section{INTRODUÇÃO}

A assistência social no Brasil, desde o início do século XX, não tinha o status de política pública; sua implementação pelo Estado ocorria marginalmente quando comparada com as políticas de saúde e de previdência social. Nessa área social era implementado um conjunto de ações assistenciais por meio de iniciativas privadas que reforçavam a existência das instituições filantrópicas e de caridade. Tais ações contavam com auxílios e subvenções fornecidos pelo próprio Estado.

$\mathrm{Na}$ segunda metade desse mesmo século, no contexto da ditadura militar, o Estado realizou uma série de reformas, que contribuíram com a exclusão dos trabalhadores nos processos de decisão e que resultaram na permanência das políticas sociais orientadas pela perspectiva do seguro social, cujo eixo estruturador era a previdência social. Porém, nos anos 1980, em um período caracterizado pela redemocratização do país, o Estado conduziu outras reformas, que levaram em consideração alguns anseios dos setores progressistas da sociedade e que se expressaram, mesmo que de forma parcial, no texto da Constituição Federal de 1988. Esta Carta Magna alterou legalmente o padrão de proteção social, tendo em vista que, ao incluir a política de saúde, de previdência e de assistência social, como pilares da seguridade social, estabeleceu um formato de proteção social mais abrangente, inclusivo e com uma orientação democrática e redistributiva. Particularmente, a assistência social tornou-se uma política pública ao ser incorporada no texto constitucional como um direito social.

Entretanto, desde a entrada do neoliberalismo no Brasil, no começo dos anos 1990, em que pesem algumas conquistas importantes possibilitadas pela mobilização e organização de setores democrático-populares, as forças conservadoras adeptas a essa racionalidade, tanto no âmbito do Estado quanto da sociedade civil, vêm impedindo a criação e/ou desrespeitando os dispositivos jurídico-políticos que tratam da assistência social e das demais políticas de seguridade social, como um conjunto integrado de ações do Poder Público e da sociedade que visam assegurar direitos sociais. Assim, a área da assistência social tem sido marcada, principalmente, pela continuidade de ações paralelas, seletivas e focalizadas, que não se orientam pela legislação que reconhece a assistência social como direito e dever do Estado (SILVA, 2014).

Diante desse cenário, este artigo procura,a partir de uma pesquisa bibliográfica e documental, analisar, por meio de um resgate histórico das principais contradições na área daassistência social no contexto da neoliberalização no Brasil, as medidas adotadas pelo governo ultraneoliberal de Bolsonaro, que vem aprofundando a manutenção de uma estrutura de ações paralelas, focalizadas e seletivas nessa área social, que não se configuram como direitos sociais, principalmente no contexto da pandemia da Corona VirusDisease, iniciada no mundo em 2019 (COVID19). 


\section{ASSISTÊNCIA SOCIAL NO CONTEXTO DA NEOLIBERALIZAÇÃO NO BRASIL}

Como uma das respostas à crise estrutural do capital eclodida nos anos 1970, "a dinâmica da neoliberalização tem agido de modo a forçar adaptações que variam muito de lugar para lugar e de época para época" (HARVEY, 2008, p. 80, grifos nossos), podendo ser apontado aqui as seguintes versões: uma ortodoxa; outra que vem sendo chamada de "progressista", mas que conserva seus princípios elementares $^{1}$, como o social-liberalismo2; e uma vertente denominada de ultraneoliberal ${ }^{3}$. Nessa direção, Antunes (2018, p. 267) destacou que no Brasil "o neoliberalismo vem se efetivando por meio de um movimento pendular, quer via governos neoliberais 'puros', quer pela ação de governos mais próximos ao social-liberalismo, sendo em ambos os casos os pressupostos fundamentais do neoliberalismo se mantêm essencialmente preservados".

De acordo com esse mesmo autor, oneoliberalismo iniciou-se no país com o governo de Fernando Collor de Mello (1990-1992), que elaborou um projeto nacional de integração subordinada ao capitalismo mundial (ANTUNES, 2005). Esse presidente da República, que também não se desvinculou do estilo tradicional de se fazer política no país, procurou pôr em prática uma "reforma" neoliberal do Estado, que na área da assistência social expressou-se por meio do veto do projeto de lei orgânica da assistência social, pela extinção da Legião Brasileira da Assistência Social (LBA), pela redução do investimento social e pelo uso dos recursos como bens pessoais e/ou como moeda de troca. A exemplo, a primeira dama da República, Rosane Malta Collor de Mello, que havia assumido a direção administrativa da LBA, esteve envolvida em corrupções, que foram constatadas pela transferência de recursos desta instituição para uma associação filantrópica, que era fictícia e dirigida pelos membros da sua família.

As constantes denúncias de corrupção e a má administração do governo Collor levaram o Congresso Nacional a abrir uma Comissão Parlamentar de Inquérito, que resultou no seu impeachment. O vice-presidente da República, Itamar Franco (1992-1994), assumiu o governo, que apenas promulgou a Lei Orgânica de Assistência Social (LOAS) em 1993 e institucionalizou o Conselho Nacional de Assistência Social (CNAS). Portanto, não ocorreu a reorganização da política de assistência social, pois este governo neoliberal direcionou seus esforços na execução do Plano de Combate à Fome e à Miséria pela Vida (1993), que não tocou no padrão de acumulação capitalista que agravava a pauperização absoluta, exatamente por estar articulado a uma política econômica neoliberal, que seguia as determinações dos organismos multilaterais, sem se preocupar com os níveis alarmantes de fome e a miséria do país.

O governo de Fernando Henrique Cardoso - FHC (1995-2002), como forma de atender um pacto de dominação burguesa, procurou consolidar uma ortodoxia neoliberal, que inviabilizava as 
conquistas dos setores democrático-populares que foram incorporadas à Constituição Federal de 1988. No mesmo dia em que tomou posse, FHC publicou a Medida Provisória (MP) n 813, de 01/01/1995, que dispõe sobre a organização da presidência da República e dos ministérios, inaugurando assim uma das marcas da sua gestão: a imposição da contrarreforma do Estado. Por meio desta MP, o governo também criou o Programa Comunidade Solidária e institucionalizou uma estrutura paralela à política de assistência social. Esta área assim foi concebida como um assunto que não deveria exigir exclusivamente a elaboração de uma política pautada em princípios e diretrizes importantes para garantir o acesso a direitos sociais. Pelo contrário, continuaria sendo vista como uma área que exige esforços da presidência da República e outros órgãos da Administração Federal para elaborar e implementar, em parceria com determinadas organizações da sociedade civil, um conjunto de ações focalizadas, sobrepostas e voltadas ao "combate" à fome e à pobreza. Como mencionou Pereira (1995, p.149), para este governo:

[...] a assistência social não é área de definição política [...]. É área de engenhosidade operativa, de campanhas, de apelos carismáticos, de mobilizações espetaculares de curto prazo [...]. Daí o fracionamento, na MP, do seu campo de atuação, a justaposição de programas dirigidos à calamidade da fome e da pobreza absoluta e a tendência em transformá-la em ação 'focalizada' e desagarrada de um projeto nacional de desenvolvimento sócio-econômico.

Durante o segundo mandato de FHC (1999-2002), em que pesem os esforços dos setores democrático-populares que lutavam pela assistência social enquanto direito nos espaços de participação e decisão (fóruns, conselhos e conferências), essa área social continuou sendo prestada por diferentes órgãos que implementavam programas direcionados ao enfrentamento da fome e da pobreza absoluta, não tendo, portanto, um comando único como prevê a LOAS. Além da continuidade do Programa Comunidade Solidária, o governo ortodoxo neoliberal de FHC ampliou em 2001 os programas nacionais de renda mínima focalizados, seletivos, que exigem contrapartidas e que são de baixo custo ${ }^{4}$. Apesar de responderem às manifestações imediatas da pobreza absoluta, essas ações assistenciais, desde então,vêm seguindo o "melhor" estilo de assistencialismo eleitoral ou de caridade pública; e que em termos estratégicos acabam assumindo o lugar dos direitos sociais. A presença delas em muitas áreas desse governo nacional 'parece indicar a 'assistencialização' das políticas sociais [que] possibilita, ainda, a ausência de uma definição clara dos critérios de transferência de recursos e a pulverização dos mesmos" (SOARES, 2001, p. 293-294).

Ainda que seja por meio de uma variante social-liberal, os governos de Luiz Inácio Lula da Silva (2003-2010) e de Dilma Rousseff (2011-2016)aprofundarama consolidação da hegemonia neoliberal, que vem promovendo, desde o meado dos anos 1990, uma verdadeira contrarreforma das políticas garantidoras de direitos sociais. Embora tenha incorporado ao "Programa de Governo 2002 
Coligação Lula Presidente", aconstrução de um sistema descentralizado e participativo para a política de assistência social, que esteve pautada na agenda da Constituinte de 1987, no processo de regulamentação dessa política no início dos anos 1990 e nas conferências nacionais dessa área realizadas no governo $\mathrm{FHC}$, o governo Lula também manteve uma estrutura paralela inicialmentecomposta pelo: Ministério Extraordinário de Segurança Alimentar e Combate à Fome, o Conselho Nacional de Segurança Alimentar e Nutricional, o Programa Fome Zero, o Fundo de Combate e Erradicação da Pobreza, o Programa Bolsa Família vinculado à Secretaria Executiva do Conselho Gestor Interministerial da presidência da República e mais tarde à Secretaria Nacional de Renda de Cidadania do Ministério do Desenvolvimento Social e Combate à Fome.

O Ministério Extraordinário de Segurança Alimentar e Combate à Fome (MESA) ${ }^{5}$ limitou-se a implementar algumas ações específicas e emergenciais do Programa Fome Zero, como o CartãoAlimentação ${ }^{6}$. A formulação, coordenação, acompanhamento e avaliação deste Programa cabia ao MESA; a implementação ficava a cargo dos governos estaduais e municipais, a partir de convênios de cooperação, que exigiam também a criação de Comissões Gestoras Locais constituidas por representantes governamentais e principalmente de setores dasociedade civil organizada. Dessa maneira, a maioria dos municipios acabou assumindo as responsabilidades de maior peso sem eles terem as condições político-administrativas e culturais adequadas. De acordo com Silva e Silva, Yazbek e Di Giovanni (2004, p.116):

Entre essas insuficiências e limites, destaca-se o despreparo do pessoal para a gestão; as limitadas condições de recurso e infra-estrutura da maioria dos municipios brasileiros [...] e, sobretudo, a prevalência de um tipo de cultura política fortemente caracterizada por posturas patrimonialistas e clientelistas, que tanto marcou a formação da sociedade brasileira. Nesse sentido, têm sido veiculadas denúncias de desvio no cadastramento das famílias beneficiárias do Cartão-Alimentação em vários municípios brasileiros, como a inclusão indevida de pessoas como prefeitos, secretários municipais, vereadores, funcionários públicos, fazendeiros e outras pessoas que não atendem o critério de inclusão no Programa.

O Conselho Nacional de Segurança Alimentar e Nutricional (CONSEA) atuou no processo de construção da política nacional dessa área social, assim como na elaboração do Sistema Nacional de Segurança Alimentar e Nutricional (SISAN) ${ }^{7}$. Dentre as diretrizes deste Sistema, destacam-se a intersetorialidade e a descentralização. Porém, puderam-se constatar avanços e limites relacionados à intersetorialidade, que estavam associados à resistência dos diferentes ministérios e outros órgãos da administração pública federal de construir um sistema integrado, o que reforçoua sobreposição, desarticulação e paralelismo das ações; à natureza, composição e participação no conselho, que estavam relacionados ao seu caráter consultivo, a escolha dos representantes da sociedade civil pelo Poder Executivo e mecanismos de controle do governo sobre a participação; e à descentralização, que como em outras áreas, caracterizou-se pela centralização do poder de decisão no governo federal e 
pela implementação de programas e ações nacionais pelos municípios, que limitam a autonomia dos gestores locais (SILVA, 2014).

O Programa Fome Zero 8 foi instituído assim que Lula assumiu a presidência da República, e em função da política econômica adotada, seu governo limitou-se a efetivar políticas especificas deste Programa, como programas de renda mínima, de doação e distribuição de cestas básicas, de aquisição e incentivo à distribuição de leite; e políticas locais, como programa de restaurantes populares e de bancos de alimentos. Assim, relegou as ações estruturais, como o programa de reforma agrária e de geração de emprego e renda. Embora este Programa contasse com os comitês gestores municipais como canais de participação social, a cultura política tradicional da grande maioria das localidades do país impediu qualquer organização que pudesse enfrentar os problemas políticoinstitucionais (SILVA, 2014).

O presidente Lula, que tinha sido um dos principais sujeitos no período da redemocratização a estimular a participação popular, tratou de seguir a tendência neoliberal voluntarista e assistencialista da participação, ao convocar toda a sociedade e 0 mundo a se solidarizarem com o que chamou de "mutirão contra a fome", que possuía três frentes de atuação: a campanha de doações de alimentos, a formação de grupos voluntários e a campanha de doações em dinheiro, cujo montante era repassado ao Fundo de Combate e Erradicação da Pobreza (FCEP)9.

Das inúmeras ações que recebiam recursos do FCEP, destacam-se os programas interministeriais que transferiam renda direta às famílias pobres, como o Bolsa Escola, o Bolsa Alimentação, o PETl; e os programas que incentivavam o empreendedorismo social, como o Comunidade Ativa e o Programa de Organização Produtiva de Comunidades Pobres, que também recebiam recursos de outras fontes. Assim, com essas ações seletivas e focalizadas na extrema pobreza e que não se constituíam como direito social, tampouco conseguiam enfrentar as várias dimensões da pobreza, o governo Lula alcançou o superávit primário, garantiu o controle dos setores mais pauperizados, como também instrumentalizou essas famílias a financiarem o capital financeiro, a partir da inserção delas no mundo das finanças.

O Programa Bolsa Família(PBF) tornou-se o principal instrumento para alcançar essa finalidade ${ }^{10}$. Desde o seu lançamento uma extensa legislação e um conjunto de aplicativos e sistemas foram criados sobre o modus operandi da sua gestão. Em novembro de 2015, os dados divulgados apontavam 13.782.217 de famílias atendidas, que receberam benefícios com valor médio de $R \$ 163,06$ (MDS, 2015). Porém, a inclusão no Programa não ocorre de imediato, pois se estipulou um teto financeiro para cada município com base na estimativa de famílias a serem beneficiadas e condicionouse também à inclusão delas a dependência de recursos orçamentários disponíveis. Desde a sua criação, este governo priorizou o gasto com esse programa e o investimento direcionado aos serviços 
socioassistenciais tem sido menor. No âmbito da seguridade social, a assistência em comparação às outras políticas que compõem esse sistema de proteção social continuou sendo aquela que recebe menos recursos. No entanto, constata-se um aumento do gasto com essa área que está atrelado e direcionado principalmente ao PBF, mas cujos resultados no tocante ao enfrentamento da pobreza tem sido menor quando se compara aos direitos da previdência e da LOAS, que tem como piso o salário mínimo ${ }^{11}$. Portanto, a gestão do PBF configura-semuito mais como uma gestão da pobreza.

De acordo com a Lei n 10.836/2004 e o Decreto n 5.209/2004, a gestão do PBF deve se dar de forma descentralizada, por meio da conjugação de esforços entre os entes federados, observada a intersetorialidade, a participação comunitária e o controle social. Particularmente, atribuiuse ao governo federal a responsabilidade pela articulação intersetorial, a supervisão e a fiscalização das ações implementadas pelos governos estaduais e municipais, que aderirem ao PBF. Em especial, coube a este governo a tarefa de disciplinar os mecanismos de funcionamento do Índice de Gestão Descentralizada (IGD). Através deste Índice, busca-se medir a qualidade da gestão descentralizada do Programa, com base na atuação dos gestores estaduais e municipais sobre a execução dos procedimentos cadastrados e dos mecanismos de controle, a implementação de ações voltadas às famílias, à articulação intersetorial e à gestão de benefícios e de condicionalidades.

Esse Índice passou a condicionar as práticas e atividades desenvolvidas no âmbito da assistência social nos estados e municípios, uma vez que os recursos são uma importante fonte para financiar a dinâmica institucional nessas esferas locais de governo. De acordo com Silva (2020), o IGD vem se traduzindo num instrumento que opera sob uma lógica hierarquizada, que centraliza e transfere recursos, a partir do cumprimento de metas, a um conjunto de ações implementadas pelos governos estaduais e municipais, como o PBF e outros programas e benefícios nacionais de transferência de renda condicionada, colocando como elemento central nos equipamentos públicos de assistência social a lógica produtivista, que intensifica o trabalho e que valoriza um saber instrumental.

Nesse contexto, onde se agravam as sequelas da "questão social" decorrentes da crise estrutural do capital, o PBF pode ser considerado a principal expressão de um padrão de seletividade do Estado, que busca conservar a esfera de interesses individuais/corporativos nessa atual ordem econômica. Embora tenha sido aprovada a Política Nacional de Assistência Social (PNAS), em 2004, que traz uma concepção de gestão de um sistema descentralizado e participativo, o governo Lula, ao priorizar políticas de ajuste estrutural, trouxe graves consequências aos mecanismos públicos de proteção social, impondo, assim, limites à efetivação do Sistema Único de Assistência Social (SUAS). Contudo, este Sistema trouxe a possibilidade de construir equipamentos públicos em territórios marcados pela presença significativa de organizações do chamado "terceiro setor" que atuam também na área da assistência social. Como apontou Rodrigues (2008, p. 28), a implantação do SUAS 
possibilitou que "nos rincões deste país, havendo orçamento para tanto, construir instrumentos mínimos de proteção social: os CRAS's. E isso não compete às ONG's, mas ao Estado e ao município" (RODRIGUES, 2008, p. 28). Tais Centros ao se configurarem como espaços não só de articulação intersetorial, mas também de mobilização social e educação popular, podem romper com as tendências conservadoras apontadas pelo CFESS (2009) no âmbito desses espaços, que convivem em tensão com as tendências progressistas direcionadas à efetivação da assistência social como direito e à construção de outra ordem societária, sem exploração e qualquer forma de opressão.

A presidente Dilma Rousseff, embora tenha promulgada a Lei $n^{0} 12.435$, de 2011 , que atualiza a LOAS e que ficou conhecida como a "Lei do SUAS",deu continuidade à política econômica neoliberal do governo anterior, mas em condições (inter)nacionais menos favoráveis. Durante o seu governo (2011-2016),a crise econômica e política, de dimensões estruturais e conjunturais, contribuiu com 0 aprofundamento das políticas de ajuste estrutural, que penalizaram os trabalhadores e garantiram os interesses de setores do capital, sobretudo do capital financeiro. Assim, na área da assistência social, o governo Dilma optou por dar continuidade ao investimento, concentrado, em ações paralelas, seletivas e focalizadas na extrema pobreza do que nos serviços socioassistenciais do SUAS.

Em 2011, por exemplo, esse governo criou o Plano Brasil sem Miséria com o objetivo de enfrentar a extrema pobreza a partir de três frentes de atuação: garantia de renda, para alívio imediato da situação de pobreza; acesso a serviços públicos; e inclusão produtiva, para aumentar as capacidades e as oportunidades de trabalho e geração de renda entre as famílias mais pobres do campo e da cidade. Este Plano contou com a participação de diferentes ministérios, dos estados e municípios, de bancos públicos e de organizações da sociedade civil. Por meio dele, o governo procurou aprimorar o PBF no enfrentamento da pobreza extrema, como também incentivar a realização de cursos de qualificação profissional, a criação de cisternas e a realização de ações do Brasil Carinhoso: um Programa criado em 2012 que procurava atender famílias com crianças de até seis anos em extrema pobreza. A ideia deste Programa era a de reforçar a transferência de renda à população beneficiária e fortalecer a educação, por meio da ampliação das vagas em creches e ações de saúde, incluindo a complementação de vitaminas e a medicação contra asma.

Aqui cabe dizer que alguns dos principais eixos de atuação do PBF, do Plano Brasil Sem Miséria e do Programa Brasil Carinhoso foram desenvolvidos por meio do SUAS. Porém, pouco promoveram uma sinergia com os serviços socioassistenciais; pelo contrário, acentuaram e vêm acentuando uma fragmentação desse Sistema, tendo em vista o investimento concentrado nestas iniciativas que também transferem renda direta à população beneficiária. Em muitos municípios brasileiros pode-se identificar uma relativa melhoria da infraestrutura dos equipamentos da proteção social básica deste Sistema em relação aos equipamentos da proteção social especial, principalmente 
porque o PBF exige -, para dar conta de uma série de normas, decretos e portarias, criadas pelo Ministério do Desenvolvimento Social e Combate à Fome (MDS) -, uma engenharia social nunca antes vista na área da assistência social (SILVA, 2014). Cabe também destacar que, apesar dessas ações serem iniciativas que no discurso oficial dos governos Lula e Dilma buscavam garantir o acesso às políticas que materializam direitos sociais, na prática encontraram e vêm encontrando limites para assegurá-los, pois o Estado vem priorizando essas ações de caráter emergencial e seletivo e dessa maneira pouco tem investido nas políticas estruturais e universais.

Com o golpe institucional quese expressou com a deposição da presidente Dilma e a posse do seu vice, Michel Temer (que também participou dos esquemas que deslocaram a base de apoio do governo) iniciou-se um "novo" período da história do país marcado pelo aumento do conservadorismo, do neofascismo e pela ofensiva ultraneoliberal, que de forma rápida, agressiva e radical vem buscando, como forma de atender os interesses do capital de dominação financeira, privatizar empresas e serviços públicos; e descontruir os direitos sociais que ainda restam. Desse modo, algumas conquistas possibilitadas com o advento da PNAS/SUAS foram duramente atacadas, pois o governo ilegítimo de Temer (2016-2018) reforçou a condição de ajuda da assistência social, por meio do congelamento dos recursos; da redução drástica do orçamento; do retorno do primeirodamismo no governo nacional; da descoordenação das ações; do descumprimento do comando único e das medidas deliberadas na conferência nacional da área; do estabelecimento de critérios ainda mais rígidos de seleção e acompanhamento dos beneficiários dos programas; do aprofundamento da precarização das condições e relações de trabalho; do incentivo ao trabalho de visitadores sociais vinculados ao Programa Criança Feliz, de voluntários; da promoção da caridade e da filantropia etc. (SILVA, 2019). Sobre o Programa Criança Feliz, o CFESS (2017) apontou em nota que:

\footnotetext{
O Criança Feliz é exógeno ao SUAS, ao SUS, à educação infantil e deslocado de todas as demais políticas públicas e direitos sociais. $\dot{E}$ um verdadeiro retrocesso!Sua operacionalização está sob a coordenação da assistência social nos entes federados, fora do SUAS - desrespeitando a tipificação nacional dos serviços socioassistenciais, o pacto federativo e os critérios de instalação dos serviços, como também a NOB-RH/SUAS e as Resoluções $n^{0}$ 17/2011 e $n^{0}$ 09/2014, que tratam dos recursos humanos nos serviços e definem quem são os/as trabalhadores/as do SUAS. (CFESS, 2017, p. 1, grifos nossos).
}

Desde a campanha para eleição da presidência da República em 2018, as propostas do candidato Bolsonaro eleito pelo Partido Social Liberal (PSL), hoje sem partido, já demonstravam que iria dar continuidade à implementação dessas medidas ultraneoliberais, como também criaria outras. De fato, seu governo ultraneoliberal e neofascista vem reforçando os traços mais tradicionais na área da assistência social. A exemplo, manteve o primeiro-damismo e deu continuidade ao Programa Criança Feliz, que desde o governo anterior vem recebendo um valor muito superior ao montante de recursos destinado aos programas, projetos e ações de gestão no âmbito do SUAS, que 
correspondem a direitos sociais previstos em lei (CFESS, 2018). Destaca-se, também, a publicação da Portaria no 2.362/2019 do Ministério da Cidadania, que visa promover a equilização do cofinanciamento federal do SUAS à Lei de Diretriz Orçamentárias e à Lei Orçamentária Anual. Segundo o CONGEMA (2020), com essa medida, o governo Bolsonaro desconsidera o pacto federativo previsto no SUAS, estabelece critérios de adequação dos repasses dos recursos e da redução por meio dessa "equilização", que coloca em risco a existência desse Sistema, principalmente nos municípios de pequeno porte.

Esse governo -, apesar de ter cumprido a promessa que fez na campanha eleitoral de pagar $013^{\circ}$ do PBF, ou seja, o pagamento do valor do auxílio financeiro em dobro aos beneficiários no final do ano -, propôs um orçamento anual do Programa para 2020 inferior ao de 2019 e sem a previsão do $13^{\circ}$ para os beneficiários ${ }^{12}$, o que demonstra não haver perspectiva para inclusão de novos beneficiários inscritos no Cadastro Único para Programas Sociais (CADÚNICO). O mesmo ocorre com o BPC, tendo em vista que, embora seja um direito assistencial voltado para idosos a partir de 65 anos e pessoas com deficiência, que tenham uma renda mensal de até um quarto do salário mínimo por pessoa, e que são incluídos como beneficiários desde que estejam dentro desse perfil -, nota-se uma morosidade no processo de liberação do benefício, a perda de validade de medidas importantes que garantiriam o $13^{\circ}$ também aos beneficiários do BPC (como a MP 898/2019), e a crescente ameaça desse governo ultraneoliberalpara realizar cortes no valor e no número de beneficiários, que veio acompanhadada publicação pelo governo da Portaria Conjunta $n^{0}$ 7/2020. Essa Portaria regulamenta regras e procedimentos de requerimento, concessão, manutenção e revisão do BPC, demonstrando, segundo a Folha de São Paulo (2020), o objetivode economizar R 10 milhões por ano.

Essas medidas ultraneoliberais do governo Bolsonaro agravaram ainda maisas consequências da pandemia da COVID-19, que vem expondo a olho nu a forma pela qual o capitalismo explora a força de trabalho. Essa pandemia não vem atingindo a todos da mesma maneira. Pelo contrário, tem sido mais letal na classe trabalhadora, principalmente nos setores mais pauperizados constituídos por homens e mulheres negras, que durante décadas têm sido os mais atingidos com a contrarreforma do Estado e das políticas sociais, sobretudo com as recentes medidas ultraneoliberais adotadas por esse governo, que resistiu em tomar alguma iniciativa na área da assistência social para enfrentar essa crise sanitária ${ }^{13}$ e, quando fez, desrespeitou a legislação que reconhece a assistência social como um direito do cidadão e um dever do Estado, ao aprofundar a manutenção de uma estrutura de ações paralelas, seletivas e focalizadas na pobreza absoluta, que não se configuram como direito assistencial. 


\section{A POLÍTICA DE ASSISTÊNCIA SOCIAL NO CONTEXTO DA PANDEMIA DA COVID 19}

A proposta de criação pelo governo ultraneoliberal de Bolsonaro de um auxílio emergencial no valor ínfimo de $\mathrm{R} \$ 200,00$, nesse contexto da pandemia em que milhões de trabalhadores e famílias estão sem emprego, trabalho e não têm acesso a nenhum beneficio assistencial ou previdenciário, demonstra um desconhecimento da LOAS, de 1993, atualizada pela "Lei do SUAS"14 de 2011, que prevê a implementação de benefícios eventuais, que correspondem às "provisões suplementares e provisórias que integram organicamente as garantias do SUAS e são prestadas aos cidadãos e às famílias em virtude de nascimento, morte, situações de vulnerabilidade temporária e de calamidade pública" (BRASIL, 2011, p. 38, grifos nossos). Essas situações de vulnerabilidade são compreendidas aqui como expressões da "questão social".

A PNAS também aponta que os serviços socioassistenciais no SUAS devem ser organizados a partir da vigilância social, da proteção social e da defesa social e institucional. Em relação à proteção social, essa política social considera que a segurança de sobrevivência ou de rendimento e de autonomia deve ser prestada através de benefícios continuados e eventuais que assegurem: "proteção social básica a idosos e pessoas com deficiência sem fonte de renda e sustento; pessoas e famílias vítimas de calamidades e emergências; situações de forte fragilidade pessoal e familiar, em especial às mulheres chefes de família e seus filhos" (BRASIL, 2004, p. 33-34, grifos nossos). Por sua vez, a Tipificação Nacional de Serviços Socioassistenciais de 2009 prevê, no âmbito da Proteção Social Especial de Alta Complexidade, a prestação de Serviço de Proteção em Situações de Calamidades Públicas e de Emergências. Portanto, a atuação da política de assistência social em situações de calamidade pública está prevista no seu marco jurídico-político. Porém, cabe aqui apontar que essa política social não cumpre sozinha a função de proteção social, tendo em vista que ela "realiza-se de forma integrada às políticas setoriais, garantindo mínimos sociais e provimento de condições para atender contingências sociais e promovendo a universalização dos direitos sociais" (BRASIL, 2011, p. 9).

Apenas no dia 20 de março de 2020, depois de quase um mês da confirmação do primeiro caso de coronavírus no Brasil, o governo Bolsonaro publicou o Decreto $\mathrm{n}^{0} 10.282$, que regulamenta a Lei $n^{0} 13.979$, de 6/02/2020, que inclui, no âmbito dos serviços públicos e as atividades essenciais, a assistência social e seu atendimento à população em estado de vulnerabilidade, que não significou nenhuma novidade, pois, como apontado, o marco jurídico-político dessa política social estabelece a sua atuação em situações de vulnerabilidade e de calamidade pública.

Além de ter desconsiderado a LOAS, o governo Bolsonaro, ao proporo Auxílio Emergencial no valor ínfimo de $\mathrm{R} \$ 200,00$, também desconsiderou a Lei $\mathrm{n}^{0} 10.835$, de 8 de janeiro de 2004, que 
institui a renda básica de cidadania.No Congresso, essa proposta foi rejeitada pela oposição, que aprovou a Lei $n^{0} 13.982$, de 2/04/2020, que estabeleceu o pagamento de Auxílio no valor de $\mathrm{R} \$ 600,00$ por três meses aos trabalhadores informais, aos chamados microempreendedores individuais, autônomos e desempregados, que não estivessem protegidos por nenhum tipo de benefício social, como previdenciário ou assistencial, exceto pelo PBF. A referida Lei também estabeleceu que fosse garantido o recebimento do Auxílio no valor $\mathrm{R} \$ 1.200,00$ para a mulher provedora da família.

Em razão da continuidade da pandemia, o governo Bolsonaro anunciou a extensão desse Auxílio Emergencial, mas reduziu o valor ao pagamento de quatro parcelas de $\mathrm{R} \$ 300,00$ até dezembro de 2020. Ao notar o impacto político-eleitoral e econômico desse Auxílio, principalmente nos estados e municípios em que não tinha tanta popularidade, o governo propôs a criação de um novo programa de transferência direta de renda chamado inicialmente de Renda Brasil e, posteriormente, de Renda Cidadã, mas que, apesar do nome, manteria as principais características neoliberaisdos programas de renda mínima.Contudo, o governo vem encontrando dificuldades orçamentárias para criar esse programa sem desrespeitar 0 teto de gastos e ainda não apresentou nenhuma previsão sobre a prorrogação do Auxílio Emergencial para 2021.

Desde o momento da implantação desse Auxílio, oseu acesso tem sido caracterizado pela burocratização e por outras inúmeras dificuldades (longas filas, falta de explicação e orientação, demora no pagamento etc.), tendo em vista a preferência do governo de investir, principalmente, num sistema paralelo, que exige a realização de cadastro em um aplicativo ou no site dessa renda emergencial, do que na rede socioassistencial e nos sistemas de informação do SUAS.

Esse sistema da política de assistência social vem sendo atingindo pelo ajuste fiscal permanente, como também as demais políticas sociais. Apesar do seu desfinanciamento, que inviabiliza a implementação dos serviços socioassistenciais e que precariza as condições e relações de trabalho, a rede sócio assistencial do SUAS conta, nos dias atuais, com 8.360 Centros de Referência da Assistência Social; 2.664 Centros de Referência Especializado da Assistência Social; 228 Centros de Referência Especializado para Pessoas em Situação de Rua (BRASIL, 2019), com 20.369 entidades privadas de assistência social inscritas nos conselhos municipais de assistência social (MDS, 2020); e com a Rede-SUAS constituída "por um conjunto de subsistemas, que são utilizados para registrar e divulgar informações sobre os recursos transferidos, acompanhar e processar dados sobre programas, serviços e benefícios, gerenciar convênios, dar suporte à gestão orçamentária etc." (SILVA, 2014, p. 288).

No entanto, a existência do SUAS em todo território nacional não significou que ele tenha sido organizado substancialmente a partir dos eixos estruturantes previstos na PNAS, a saber: matricialidade sociofamiliar; descentralização e territorialização; novas bases para a relação entre 
Estado e sociedade civil; financiamento; controle social; política de recursos humanos; e a informação, o monitoramento e a avaliação. A pandemia da COVID-19 demonstrou o desrespeito e o descaso dos governos (ultra)neoliberais, sobretudo do governo Bolsonaro, com esse sistema de organização da gestão e oferta de serviços, programas, projetos e benefícios. Como apontou Melatti (2020, n.p),

[...] a pandemia escancarou as insuficiências do SUAS - equipes desfalcadas, número de CRAS, CREAS, CENTROS POP deficitários, em face da população a ser atendida, contratos de trabalho precarizados, ausência de política sólida de educação permanente, incapacidade de gestão da assistência social em todos os níveis, desrespeito, por parte do Executivo, às instância de controle social, dentre outras. [...]. Há uma retórica sendo difundida de que os serviços de assistência social são essenciais [e são], mas não há recurso financeiro suficiente que, de fato, materialize esse 'reconhecimento' acerca da sua essencialidade.

De acordo com Bichir e Stuchi (2020), a assistência social no contexto da pandemia tem dado a sua contribuição como uma política social historicamente relegada. As autoras acrescentam que o esvaziamento da agenda do SUAS, nesse cenário, acentua o risco do paralelismo e da sobreposição de ações, com retorno a práticas voluntaristas e fragmentadas, que estão na contramão das diretrizes atinentes à assistência social como direito e dever do Estado. Além disso, reforçam que as provisões suplementares e provisórias destinadas às famílias em situação de vulnerabilidade e de calamidade pública estão previstas na LOAS, o que "não se verifica no atual regramento [do Auxílio Emergencial]" (BICHIR; STUCHI, 2020, n. p).

O Ministério da Cidadania publicou no dia 15 de abril de 2020 a Portaria $n^{0} 58$, que aprovou a Nota Técnica $n^{0}$ 20/2020. Essa medida trata das orientações gerais sobre a regulamentação, a gestão e a oferta de benefícios eventuais no contexto de enfrentamento aos impactos da pandemia da COVID-19 no âmbito do SUAS. No dia seguinte, o presidente Bolsonaro editou a Medida Provisória n 953 , de 16/04/2020, que abre crédito extraordinário para o enfrentamento do novo coronavírus em favor do Ministério da Cidadania, no valor de R\$2.550 bilhões. Contudo, apenas no dia 29 de abril de 2020, este Ministério publicou a Portaria $n^{\circ} 369$, que dispõe acerca do atendimento do CADÚNICO no Distrito Federal e nos municípios que estejam em estado de calamidade pública ou em situação de emergência decorrente da infecção humana provocada pelo novo coronavírus. Nessa Portaria, este Ministério considerou o crédito extraordinário, como um recurso emergencial para a execução de ações socioassistenciais e estruturação da rede do SUAS. Entretanto, impôs, por meio dessa medida, regras referentes à aquisição de equipamentos de proteção individual dos trabalhadores, de alimentos destinados aos usuários; e ligadas ao cofinanciamento de ações socioassistenciais, que, de um modo geral, estão condicionadas à existência de determinadas unidades de atendimento, ao número de trabalhadores da assistência social; a um perfil de usuários (pessoas com deficiência, em situação de rua, desabrigados, desalojados, imigrantes, idosos e 
famílias), à gradativa desmobilização dessas ações sociassistenciais pelo gestor da política de assistência social; e ao cumprimento pelos entes da federação elegíveis de envio de Termo de Aceite e Compromisso, Plano de Ação e procedimentos de prestação de contas. Portanto, estaPortaria $n^{0} 58$ configura-se como uma medida burocrática, seletiva e emergencial, que, embora produza algum efeito em decorrência das inúmeras fragilidades ou insuficiências do SUAS, não altera o desfinanciamento e o desmonte deste Sistema.

Não é por acaso, que a Frente Nacional de Defesa do Sistema Único de Assistência Social - FNDSUAS (2020) vem exigindo nesse contexto da pandemiaa recomposição efetiva do orçamento nessa área, tendo em vista que o CNAS aprovou o valor aproximado de 2,7 bilhões, mas a Lei Orçamentária Anual autorizou apenas 1.3 bilhões; a revogação da Portaria n 2.362/2019, por considerar que essa medida reduz recursos, equalizados de acordo com a disponibilidade orçamentária anual; a implantação da Renda Básica de Cidadania, com garantia de um salário mínimo, para todos (as) que estejam desprotegidos socialmente, particularmente aos milhões de brasileiros (as) com rendimento inferior a $1 \frac{1}{2}$ salário mínimo; a inclusão de 3,5 milhões de famílias que estão na fila do PBF, com antecipação da $13^{a}$ parcela; e o acesso a mais de 28 milhões de famílias do CADÚNICO, que corresponde a 77 milhões de pessoas.

Somam-se a essas reivindicações, a caracterização oficial da política de assistência social, por todas as esferas de governo, como política essencial; a orientação e regulação pelos gestores quanto à reorganização dos serviços e a ampliação dos benefícios socioassistenciais, de modo a promover a segurança dos usuários e dos trabalhadores; a criação de um protocolo nacional para enfrentamento da crise sanitária que atinge os usuários do SUAS; a garantia de segurança e condições de trabalho neste Sistema, conforme orientações das autoridades sanitárias e dos órgãos competentes nacionais e internacionais; a implantação do aluguel social em todo o país; a proteção especial as famílias e indivíduos em situações de maior vulnerabilidade, com a disponibilização de recursos para o acolhimento emergencial e adequado à população em situação de rua e migrantes; a incorporação na chamada Agenda Social (Projeto de Lei $n^{0}$ 200/2019) dos interesses e das demandas sociais e político-administrativas dos governos municípios e da população usuária; e a liberação de recursos do IGDSUAS em valor ampliado e suficiente para a compra emergencial de materiais de prevenção ao contágio, para a disponibilização em todos os equipamentos da política de assistência social (FNDSUAS, 2020).

No âmbito da seguridade social, a FNDSUAS (2020), como outras frentes nacionais vinculadas às demais políticas de proteção social, vem exigindo a extinção da Emenda Constitucional 95/2016 e o fortalecimento do papel do Estado na garantia dos direitos sociais à população, como forma de enfrentar essa crise sanitária, que vem agravando a crise estrutural do capital. 
Entretanto, distante dessas reais necessidades da política de assistência social, o governo Bolsonaro vem publicando portarias e notas técnicas, que desconsideram a participação, no processo de elaboração, das instâncias de controle social democrático; que reforçam o enfrentamento das expressões da "questão social" pelo viés moralizante e psicologizante; e que violam assim os direitos sociais. Depois da criação da Nota Técnica n 11/2019, da Coordenação Geral de Saúde Mental, Álcool e outras Drogas, que reduz, por um lado, a atuação dos Centros de Atenção Psicossocial; e, por outro, fortalece as chamadas "comunidades terapêuticas", que são ineficientes nessa forma de atenção, principalmente por se configurarem, em termos práticos, como espaços de violações de direitos, o governo, recentemente, por meio da Secretaria Nacional de Assistência Social, do Ministério da Cidadania, publicou a Portaria Conjunta $n^{0} 4$, de 22/10/2020, que aprova a orientação técnica conjunta para a atuação intersetorial e integrada entre a rede socioassistencial e as "comunidades terapêuticas" no enfrentamento da pandemia da COVID-19 junto à população em situação de rua, que faz uso abusivo de substâncias psicoativas. Essa Portaria expressa o uso da pandemia pelo governo Bolsonaro para aprofundar um projeto ultraneoliberal, que descaracteriza a política de assistência social e de saúde mental como direitos sociais. Em particular, que estabelece uma forma de atendimento contrária ao Código de Ética Profissional de Assistentes Sociais de 1993, fragilizando, assim, não só o Serviço Social, mas todas as instituições e organizações que lutam por uma sociedade politicamente e humanamente emancipada ${ }^{15}$.

\section{CONCLUSÃO}

Em suma, pode-se dizer quea dinâmica da neoliberalização no Brasil vem exigindo uma determinada configuração do Estado, na qual não há espaço para a proteção social pública e universal da população, em particular para efetivação de uma política de assistência social como um direito do cidadão e dever do Estado. Em que pesem as resistências dos setores democráticopopulares, a análise dos governos (ultra) neoliberais e dos seus ataques à política pública de assistência social demonstrou a criação e a manutenção de uma estrutura composta por ações paralelas, seletivas e focalizadas na pobreza absoluta, que não se configuram como direito assistencial. A implementação de alguns dos eixos dessas ações por meio do SUAS tem contribuído muito mais para fragmentação desse Sistema, tendo em vista o repasse de recursos destinados às ações vinculadas principalmente à proteção social básica. Além disso, acabam por descaracterizara construção deste Sistema na perspectiva da garantia do direito à assistência social, pois são ações que seguem o "melhor"estilo de assistencialismo eleitoral e/ou de caridade pública, como é caso dos programas de renda mínima e, sobretudo, do Programa Criança Feliz. 
Com a pandemia da COVID-19, o governo ultraneoliberal de Bolsonaro vem aprofundando essa estrutura de ações paralelas, seletivas e focalizadas, que desrespeitam a legislação que reconhece a assistência social como um direito social. Além de ter demorado a tomar alguma iniciativa para enfrentar essa crise sanitária nessa área social, o governo quando ofez, desrespeitou o marco jurídico da política de assistência social. O financiamento diminuto voltado a essa política social também vem demonstrando que -, embora essa área social seja considerada uma atividade essencial no enfrentamento da pandemia -, o governo não vem reconhecendo, de fato, a assistência social como uma política essencial no enfrentamento dessa calamidade pública.

Nesse contexto de regressão dos direitos sociais decorrentes das contrarreformas das políticas sociais, a criação do Auxílio Emergencial, que desconsiderou a previsão de benefícios eventuais na LOAS e a Lei $n^{0} 10.835$, de 8/01/2004, que institui a renda básica de cidadania, embora atenda as necessidades mínimas de aproximadamente 67,2 milhões de pessoas, que correspondem a 43,9\% dos domicílios brasileiros (IBGE, 2020), tem sido útil principalmente à reprodução do capital de dominação financeira, na medida em que ações de transferência direta de renda à população pobre e extremamente pobrevêm incentivando o consumo de bens e serviços, como uma forma de atenuar as falhas de mercado.

\section{REFERÊNCIAS}

ANTUNES, R. 0 privilégio da servidão: o novo proletariado de serviços na era digital. São Paulo: Boitempo, 2018.

ANTUNES, R. A desertificação neoliberal no Brasil (Collor, FHC e Lula). Campinas: São Paulo: Autores Associados, 2005.

BOSCHETTI, I.; SALVADOR, E. Orçamento da seguridade social e política econômica: perversa alquimia. Serviço Social \& Sociedade, n. 87, São Paulo: Cortez, 2006.

BICHIR, R.; STUCHI, C. G. A assistência social e a pandemia: contribuições de uma política relegada. Estadão, 13 abr. 2020. Disponível em: A assistência social e a pandemia: contribuições de uma política relegada (estadao.com.br). Acesso: 28 nov. 2020.

BRASIL. Censo SUAS de 2019. Brasília: MDS, 2019. Disponível em https://aplicacoes.mds.gov.br/snas/vigilancia/index2.php. Acesso em: 20 out. 2020.

BRASIL. Lei $n^{0}$ 12.435, de 6 de julho de 2011. Altera a Lei $n^{0}$ 8.742, de 7 de dezembro de 1993, que dispõe sobre a organização da assistência social. Brasília, MDS, 2011.

BRASIL. Lei n $^{12.435}$, de 6 de julho de 2011. Altera a Lei n 8.742, de 7 de dezembro de 1993, que dispõe sobre a organização da assistência social. Brasília, MDS, 2011. 
BRASIL. Política nacional de assistência social. Brasília: MDS, 2004.

CASTELO, R.O Canto da serei: social-liberalismo, novo desenvolvimentismo e supremacia burguesa no capitalismo dependente brasileiro. Revista Em Pauta, n. 31, v. 11, Rio de Janeiro: UERJ, 2013.

CFESS. Em defesa da política de assistência social e do trabalho de assistentes sociais. In: CFESS Manifesta, Brasilia, 2018. Disponível em: http://www.cfess.org.br/arquivos/2018-CfessManifesta2SeminarioAssistencia-Site.pdf. Acesso em: 13 set. 2020.

CFESS. Nota pública por que dizer não ao Programa Criança Feliz. Brasília: CFESS, 7 de março de 2017.

CFESS. Parâmetros para atuação de assistentes sociais na política de assistência social, Brasília: CFESS, 2009.

CISLAGHI, J. F. Parte III: O ultraneoliberalismo e a política dos ressentidos. Esquerda Online, Rio de Janeiro, 25 jun. 2020. Disponível em: https://esquerdaonline.com.br/colunistas/juliana-fiuza-cislaghi/. Acesso em: 24 jul. 2020.

CONGEMAS. Posicionamento do CONGEMAS acerca da Portaria $n^{0}$ 2.362. CONGEMAS, Brasília, 12 fev. 2020. Disponível em: http://www.congemas.org.br/Publicacao.aspx?id=112428. Acesso em: 24 jul. 2020.

CRESS $6^{a}$. REGIÃO. Nota pública em repúdio à Portaria Conjunta $n^{0} 4$, de 22 de outubro de 2020 publicada pela Secretaria Nacional de Assistência Social. Belo Horizonte, 23 out. 2020. Disponível em: www.cress-mg.org.br/site/. Acesso em: 24 out. 2020.

FILGUEIRAS, L.; GONÇALVES, R. A economia política do governo Lula. Rio de Janeiro: Contraponto, 2007.

FNDSUAS. FRENTE NACIONAL DE DEFESA DO SISTEMA ÚNICO DE ASSISTÊNCIA SOCIAL. Enfrentamento ao novo coronavírus, assistência social e a proteção à população mais vulnerável, mar. 2020. Disponível em: http://www.cresspr.org.br/site/. Acesso em: 13 set. 2020.

FOLHA DE SÃO PAULO.Bolsonaro não prevê novos atendidos pelo Bolsa Família em 2020. São Paulo, 2 dez. 2019. Disponível: https://www1.folha.uol.com.br/mercado/2019/12/governo-bolsonaronao-preve-novos-atendidos-pelo-bolsa-familia-em-2020. Acesso em: 19 set. 2020.

FOLHA DE SÃO PAULO. Bolsonaro não prevê novos atendidos pelo Bolsa Família em 2020. São Paulo, 2 dez. 2019. Disponível: https://www1.folha.uol.com.br/mercado/2019/12/governo-bolsonaronao-preve-novos-atendidos-pelo-bolsa-familia-em-2020. Acesso em: 19 set. 2020.

FRASER, N.; JAEGGI, R. Capitalismo em debate: uma conversa na teoria crítica. São Paulo: Boitempo, 2020.

HARVEY, D. 0 neoliberalismo: história e implicações. São Paulo: Edições Loyola, 2008.

IBGE. PNAD-COVID-19. Brasilia, 2020. Disponível em: https://covid19.ibge.gov.br/pnad-covid/. Acesso em: 26 out. 2020. 
LOPES, M. H. C.; RIZZOTTI, M. L. Amaral. Covid19 e proteção social: a contribuição do Sistema Único de Assistência Social - SUAS. In: CASTRO, D.; DAL SENO, D.; POCHMANN, M. Capitalismo e a Covid-19: um debate urgente. São Paulo: 2020.1 v. :gráfs., tabs.

MAURIEL, A. P. O. Pobreza, seguridade e assistência social: desafios da política social brasileira. Revista Katálysis, v. 13, p. 173-180, 2010.

MDS. Consulta entidades privadas. Brasília, 20 out. 2020. Disponível em:

https://aplicacoes.mds.gov.br/cneas/publico/xhtml/consultapublica/pesquisar.jsf . Acesso em: 20 out. 2020.

MDS. Manual do Índice de Gestão Descentralizada Municipal do Programa Bolsa Família e do Cadastro Único. Brasília: MDS, 2012.

MDS. Programa Bolsa Família. Brasília, 2015.

MELATTI, K.Coronavírus: e quem trabalha na política de assistência social? In: CFESS Entrevista, Brasília, 20 jun. 2020. Disponível em: http://cress-sc.org.br/2020/06/20/coronavirus-e-quem-trabalhana-politica-de-assistencia-social/. Acesso em: 13 set. 2020.

PEREIRA, P. A. P. Reflexões sobre a medida provisória $n^{0} 813$, de 01/01/95. In: Serviço Social e Sociedade, n 47, São Paulo: Cortez, 1995.

RODRIGUES, M. P. Balanço crítico do SUAS: assistência x assistencialização. In: Em Foco, ed. 5, Rio de Janeiro: CRESS-7ª Região, 2009.

SILVA e SILVA, M. O. da; YAZBEK, M. C.; GIOVANNI, G. di. A política social brasileira no século XXI: a prevalência dos programas de transferência de renda. São Paulo: Cortez, 2004.

SILVA, R. R. da.(Des)centralização, contrarreforma do Estado e política de assistência social no Brasil. 2014. Tese (Doutorado em Serviço Social) - Escola de Serviço Social da Universidade Federal do Rio de Janeiro, Rio de Janeiro, 2014.

SILVA, R. R. da. A participação do Serviço Social na construção da política pública de assistência social. Revista Libertas, v. 19, p. 1-20, 2019.

SILVA, R. R. da. Contrarreforma do Estado, gerencialismo e política de assistência social no Brasil. In: Temporalis, Brasília (DF), ano 20, n. 39, p. 27-42, jan./jun. 2020.

SOARES, L. T. R. Ajuste neoliberal e desajuste social na América Latina. Petrópolis: RJ: Vozes, 2001.

\section{Notas}

1 Segundo Fraser, os "movimentos, que crescem em quase todo país do histórico centro do capitalismo, representam a resposta previsível ao 'neoliberalismo progressista' hegemônico do tempo presente, o qual cinicamente lança mão de apelos à "justiça" enquanto amplia a expropriação e corta o apoio público à reprodução social" (FRASER; JAEGGI, 2020, p. 12). 
2 De acordo com Castelo (2013, p. 121), "o social-liberalismo surgiu nos centros imperialistas em resposta à crise conjuntural vivenciada pelo capitalismo em meados dos anos 1990, com as crises financeiras nos países dependentes (México, Tigres Asiáticos, Rússia, Brasil, Argentina) e o tímido fortalecimento das forças políticas de contestação da ordem, como os ativistas do Fórum Mundial e o Exército Zapatista".

${ }^{3}$ Sobre a ascensão do ultaneoliberalismo após a crise de 2008 e com a vitória de candidatos da extrema direita a chefes de Estado, como EUA e Brasil, ver Cislaghi (2020).

${ }^{4}$ As primeiras experiências de políticas ou programas de renda mínima no Brasil surgiram, na década de 1990, em alguns municípios da Federação, como Ribeirão Preto, Campinas e em alguns estados, como São Paulo e Distrito Federal. Datam também dessa época as primeiras propostas que seriam implantadas pelo governo federal. Em 1996 este governo lançou o Benefício de Prestação Continuada (BPC) e o Programa de Erradicação do Trabalho Infantil (PETI). Porém, foi no ano de 2001 que ampliou as políticas ou programas interministeriais que transferem renda direta aos seus beneficiários, como: 0 Bolsa-Escola, do Ministério da Educação; o Bolsa Alimentação, do Ministério da Saúde; o Programa Agente Jovem, do Ministério da Previdência e Assistência Social; e o Auxílio Gás, do Ministério das Minas e Energia, criado em 2002.

5 Este ministério foi criado pela Medida Provisória $\mathrm{n}^{0}$ 103, de 1 de janeiro de 2003. Destaca-se no campo das suas competências: a formulação e coordenação da Política Nacional de Segurança Alimentar e Nutricional (PNSAN); a participação da sociedade civil no estabelecimento das diretrizes dessa política; e a articulação entre as políticas e programas intergovernamentais e as ações não-governamentais ligadas à produção alimentar, alimentação e nutrição. Todavia, durante a sua existencia, não havia recursos humanos em quantidade adequada, apenas o ministro José Graziano e quatro auxiliares, que se envolveram em intensos conflitos interministeriais (SILVA, 2014).

${ }^{6}$ Tal Cartão foi criado com a Medida Provisória no 108, de 27 de fevereiro de 2003 e buscou garantir às famílias em situação de insegurança alimentar, uma renda mínima ou acesso a alimentos em espécie. Embora estivesse associado a ações estruturantes, tinha sérias limitações, como o valor de $R \$ 50,00$ por familias com uma renda per capita mensal de até meio salário mínimo, a duração máxima de dezoite meses e a inclusão de seus beneficiários condicionada à dotação orçamentária prevista.

7 O CONSEA foi revigorado por meio do Decreto $n^{0} 4.582$, de 30 de janeiro de 2003, que regulamentou 0 seu funcionamento como órgão de assessoramento da presidência da República no que se refere às diretrizes gerais da Política Nacional de Segurança Alimentar e Nutricional (PNSAN). O SISAN, criado pela Lei n 11.346, de 15 de setembro de 2006, passou a ser constituído pelo CONSEA, pelas conferências e órgãos intergovernamentais, instituições privadas sem fins lucrativos e câmara intersetorial.

80 projeto deste Programa havia sido criado pela organização não-governamental Instituto Cidadania vinculado ao PT. Essa proposta envolvia todos os níveis governamentais, o engajamento da sociedade organizada, a conjunção de políticas estruturais, específicas e locais, além de prever a reativação do CONSEA. De um modo geral, tal proposta seguia a tendência de propor a implementação de um conjunto de políticas aos estados e municípios, cuja maioria dependia das parcerias com os setores da sociedade civil.

9 O FCEP foi criado pelo Decreto $n^{0} 4.564$, de 01 de janeiro de 2003, que definiu o MESA como órgão gestor e 0 funcionamento do seu Conselho Consultivo e de Acompanhamento, presidido pelo ministro ou representantes da área da segurança alimentar e nutricional, pelos secretários-executivos dos ministérios (do Planejamento, Orçamento e Gestão; Educação; Saúde; Desenvolvimento Agrário; Integração Nacional; Assistência e Promoção Social; Secretário Especial dos Direitos Humanos da Presidência da República) e por um representante da sociedade civil de cada um dos respectivos conselhos dessas pastas.

${ }^{10} \mathrm{~A}$ criação deste Programa tem estreita relação com uma série de dificuldades operacionais e de gestão do Fome Zero em implementar suas ações previstas em seu projeto. Após realizar um diagnóstico sobre os programas que transferiam renda direita às famílias pobres e extremamente pobres, o governo federal constatou vários problemas, como desarticulação interinstitucional e intergovernamental, superposição de ações e de usuários, baixa cobertura, pulverização de recursos e limitação dos instrumentos de avaliação. Dessa maneira, tratou de unificar quatro programas interministeriais (Bolsa Escola/Ministério da Educação, Bolsa Alimentação/Ministério da Saúde e Auxílio-Gás/Ministério das Minas e Energia e Cupom Alimentação/MESA), a maioria lançado no segundo governo $\mathrm{FHC}$, em um único programa: o Bolsa Família, que pertencia à Secretaria Executiva do Conselho Gestor Interministerial da presidência da República. Este Programa foi criado pela Medida Provisória $n^{0}$ 132, de 20 de outubro de 2003 e busca transferir uma renda mínima às famílias pobres e extremamente pobres de todo o país, e que associa o recebimento do auxílio financeiro ao cumprimento de condicionalidades nas áreas da saúde, educação e assistência social. 
${ }^{11}$ Filgueiras e Gonçalves (2007) comprovam essa afirmação com seus estudos realizados sobre o Bolsa Família. Boschetti e Salvador (2006) também reforçam essa tendência: "as principais orientações dos programas e ações planejadas no PPA do atual governo: fortalecimento de benefícios de transferência de renda como BPC e Bolsa Família; apenas manutenção de ações protetivas e socioeducativas, com crescimento pífio de recursos que não alcançam mais de $5 \%$ dos recursos do FNAS" (Idem., 2006, p. 50).

12 Segundo a Folha de São Paulo (2019, n.p), "o projeto de Orçamento elaborado pela equipe econômica reservou $R \$ 29,5$ bilhões para o programa no próximo ano - menos que os $\mathrm{R} \$ 32$ bilhões de 2019 e sem a previsão do $13^{\circ}$ para beneficiários, prometido pelo presidente".

13 Segundo Lopes e Rizzotti (2020, p. 134), "no que concerne especificamente às medidas na circunscrição da crise atual, vale destacar que há um retardo proposital em relação às medidas de proteção social, particularmente, da política de assistência social".

14 Uma análise crítica das alterações na LOAS de 1993 pode ser encontradas em Mauriel (2010) e em Silva (2014).

${ }^{15}$ Conferir também CRESS 6a . Região (2020, p.n), "nota pública em repúdio à Portaria Conjunta $n^{0} 4$, de 22 de outubro de 2020 publicada pela Secretaria Nacional de Assistência Social”. 